Publicación semestral. ISSN 2215-4906

Volumen 81 - Número 1 Julio - Diciembre 2021

\title{
Pensar la educación desde la colaboración. El Mitote como un trabajo colectivo
}

\author{
Thinking about education from collaboration. \\ Mitote as a collective work \\ Adriana Raggi Lucio \\ María de Guadalupe Sánchez Estrada
}

DOI 10.15517/es.v81i1.47642

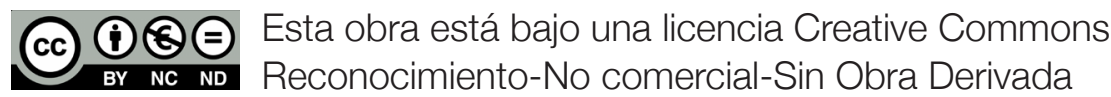




\title{
Pensar la educación desde la colaboración. El Mitote como un trabajo colectivo
}

\section{Thinking about education from collaboration. Mitote as a collective work}

\author{
Adriana Raggi Lucio ${ }^{1}$ \\ Universidad Nacional Autónoma de México \\ Ciudad de México, México \\ María de Guadalupe Sánchez Estrada ${ }^{2}$ \\ Universidad Nacional Autónoma de México \\ Ciudad de México, México
}

Recibido: 12 de febrero de 2021 Aprobado: 09 de marzo de 2021

\begin{abstract}
Resumen
Este texto pretende analizar cómo se abordó la relación entre educación y comunidad en los Mitotes de colaboración y exploración sobre la educación artística desde Simón Rodríguez, Juan Acha y Melquiades Herrera. A través de la relatoría de una experiencia y el trabajo con el archivo del evento, nos aproximamos a lo ocurrido en este encuentro, el cual se formuló a partir de educadores como Simón Rodríguez, Juan Acha, Melquiades Herrera y Lia García, así como de nuestras experiencias en la educación artística y diseñística. El texto revela cómo el evento rescató ideas de una educación que parten de lugares alejados de la dominación y acercados al diálogo entre iguales.

1 Profesora y Coordinadora de la División de Investigación de la Facultad de Artes y Diseño, Universidad Nacional Autónoma de México. Doctora en Historia del Arte. ORCID: 0000-0002-58328098. Correo electrónico: araggi@fad.unam.mx

2 Profesora adjunta y Gestión de Proyectos en la División de Investigación en la Facultad de Artes y Diseño, Universidad Nacional Autónoma de México. Licenciada en Arte y Diseño. ORCID: 00000001-6448-4735. Correo electrónico: mgsanchez@fad.unam.mx
\end{abstract}


Palabras clave: arte; diseño; comunidad; investigación; educación; debate

\begin{abstract}
This text aims to analyze how the relationship between education and community was addressed in the Mitotes of collaboration and exploration on artistic education from Simón Rodríguez, Juan Acha and Melquiades Herrera. We approached, through the report of an experience and the work with the archive of the event, to what happened in the meeting, which was formulated from educators such as Simón Rodríguez, Juan Acha, Melquiades Herrera and Lia García and our experiences in art and design education. The text reveals how the event rescued ideas of an education that starts from places far from domination and closer to dialogue between equals.
\end{abstract}

Keywords: art; design; community; research; education; research; discussions 
Pensar la educación desde la colaboración.

Dossier

El Mitote como un trabajo colectivo

\section{Desde aquí hablamos}

Abrimos este texto con una primera postura: declaramos que escribimos de forma inclusiva con una " $x$ ", como una crítica que se adhiere a los discursos auto-narrativos y auto-enunciativos que acuerpan las luchas de todxs nuestrxs aliadxs, quienes desde muchas trincheras buscan que la legitimidad de sus luchas epistémicas sea reconocida y respetada. Asimismo, escribimos en plural como una forma auto-organizativa que apuesta por la adhesión electiva como estrategia política, que une en vez de dividir, que colectiviza en lugar de individualizar, que apuesta por la confianza en un nosotrxs electivo y no en el miedo naturalizado al otrx, quien es visto como "enemigx". Sin embargo, no buscamos construir desde una mirada romantizada o ingenua; por ello, en el acto electivo hemos encontrado las herramientas que mantienen la autonomía y la dignidad, pues en este se incluye necesariamente el diálogo, de todos los tipos y de todas las formas.

La capacidad y la apertura para dialogar crean la posibilidad de suscribir, negar, acotar, re-definir, acordar, discordar y matizar, no para disuadir a nadie, sino para darnos la oportunidad de mirar al mundo desde muchas miradas. Lo hacemos así porque nos parece necesario y nos negamos a sumarnos a dinámicas epistémicas que invisibilizan voces y haceres, al estar suscritas a la práctica del régimen del pensamiento heteronormativo y hegemónico que desconfigura los sentimientos y todo lo relacionado con lo afectivo, pues para nosotrxs todas las narrativas importan... Y entonces, hablamos desde ahí.

\section{Para empezar}

Mitotes de colaboración y exploración sobre la educación artística desde Simón Rodríguez, Juan Acha y Melquiades Herrera fue una exploración del grupo de investigación Mitote ICDAC (Intervenciones Críticas desde el Arte Contemporáneo), el cual está conformado por docentes de la Facultad de Artes y Diseño (FAD) de la Universidad Nacional Autónoma de México (UNAM), que hacen investigación en educación artística y diseñística4. Los Mitotes surgieron de un cuestionamiento al coloquio ¿Qué saben los artistas? La educación artística como constructora de conocimiento. El pos-

3 Nota editorial: en este artículo se respeta la posición de las personas autora con respecto al uso de la ' $x$ ' como marcador inclusivo, a pesar de que esta forma no se encuentra dentro del uso normativo del español ni se apega a las políticas de lenguaje inclusivo de la institución editora.

${ }^{4}$ Para más información se puede consultar mitote.org 
grado en Artes y Diseño y otras experiencias de formación académica que hicimos un año antes y que se comportó de forma tradicional. A partir de darnos cuenta que ese coloquio no lograba generar un efecto colaborativo, apelamos al concepto de Mitote: fiesta colectiva para el convivio, la charla cercana y la gratitud por la escucha desinteresada, para que una reunión académica se generara a través de lo común.

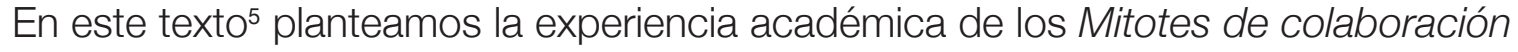
y exploración sobre la educación artística desde Simón Rodríguez, Juan Acha y Melquiades Herrera que se llevaron a cabo en 2019 y que constaron de cuatro encuentros: El mitote de Melquiades Herrera y la educación performática; El mitote de Simón Rodríguez y la educación colectiva; El mitote de Juan Acha y la educación en investigación, y el Gran Mitote, En el afuera del adentro con Lía García. A partir del evento, consideramos que las actividades académicas que generamos desde la universidad pública deben partir de nuestras discusiones colectivas. Además, es necesario que, de manera auto-reflexiva, ponderemos la observación de lo que ocurre en y a partir de dichas actividades. Pensamos que, como dice Benjamín Berlanga, es necesario "no educar sobre el mundo, sino educar en el mundo" (Klorenzini, 2011, 04:33) para así sumar esfuerzos dirigidos a generar un cambio en los procesos educativos que producen violencia en las aulas y fuera de ellas. No nos interesan los procesos que parten de la idea de que "la letra con sangre entra" y que reproducen un sistema fundado en la violencia y en las jerarquías. Foucault nos hace ver que estos procesos educativos parten de la vigilancia:

La organización de un espacio serial fue una de las grandes mutaciones técnicas de la enseñanza elemental. Permitió sobrepasar el sistema tradicional (un alumno que trabaja unos minutos con el maestro, mientras el grupo confuso de los que esperan permanece ocioso y sin vigilancia). Al asignar lugares individuales, ha hecho posible el control de cada cual y el trabajo simultáneo de todos. Ha organizado una nueva economía del tiempo de aprendizaje. Ha hecho funcionar el espacio escolar como una máquina de aprender, pero también de vigilar, de jerarquizar, de recompensar (Foucault, 2002, p. 135).

${ }^{5}$ Este es un trabajo realizado con el apoyo del Programa UNAM-DGAPA-PAPIME PE404520). 
Pensar la educación desde la colaboración.

Dossier

El Mitote como un trabajo colectivo

\section{Los mitotes}

Para el grupo de investigación Mitote ICDAC la escuela no debe ser una máquina de aprender; asimismo, cuestionamos la educación que se basa en el binomio enseñar-aprender y no creemos que sea el único espacio donde se comparten saberes. Por esto, partimos de teorías rebeldes como las de Joseph Beuys y su concepto de profesor artista, cuando dice que su obra artística más importante es el acto de ser profesor (Klüser, 2006); María Acaso (2018) y el acto pedagógico como una referencia de la enseñanza como un momento de entendimiento; Paulo Freire (2005) y la pedagogía del oprimido como una búsqueda de liberar a quien aprende a través de evitar una educación violenta; Luis Camnitzer (2012) y la educación como fraude que busca cuestionar el sistema del arte desde el momento de la formación; Pablo Helguera (2011) y el arte social que habla de estrategias pedagógicas como un medio para dirigirse a problemas sociales, y bell hooks (2003) y la educación como comunidad para erradicar la violencia y el racismo. Así, partimos ante un sistema educativo globalizado, cuantificado y sostenido en un eficientismo burocrático que genera una otrificación institucionalizada. Entendemos otrificación desde Antonio Corona, como:

un acto de violencia simbólica, un ejercicio de poder sobre el otro para situarlo desfavorablemente en comparación con la propia identidad. De manera más precisa, llamamos otrificación a la negación de la complejidad humana en aquellas personas que categorizamos como ajenos a nuestros grupos identitarios, y su reducción a características definitorias que, generalmente, calificamos como indeseables (Corona, 2018, p. 49).

Para responder a esto, hemos ensayado estrategias de investigación artística sostenidas desde diversas prácticas pedagógicas. Asimismo, hemos buscado que, desde la mediación y la autoedición, sea posible articular una experiencia significativa de la educación y las prácticas artísticas. Estos esfuerzos nos han llevado a observar que esta apuesta metodológica no solo es posible, sino que genera procesos afectivos de construcción de comunidad que transforman la experiencia educativa al interior de las aulas de la Facultad de Artes y Diseño (FAD) en un acto de acuerpamiento y resistencia electiva. Una vez que desordenamos y desjerarquizamos el acto pedagógico, nos volvemos partícipes en el aula junto con Ixs estudiantes, Ixs adjuntxs y Ixs invitadxs, y bajo diferentes circunstancias nos acompañamos en el proceso de compartir saberes. De ese modo, se busca tejer un acto pedagógico desde lo teórico, lo práctico, lo experiencial y lo sensible, con el fin de que el

ESCENA. Revista de las artes, 2021, Vol. 81, Núm. 1 (julio-diciembre), pp. 261-281 
estudiante se localice en un espacio académico que Ix implique profundamente y que propicie la activación de espacios en los que sea posible habitar situadamente la experiencia educativa, personal y comunitaria.

Imagen 1. Programa de los Mitotes

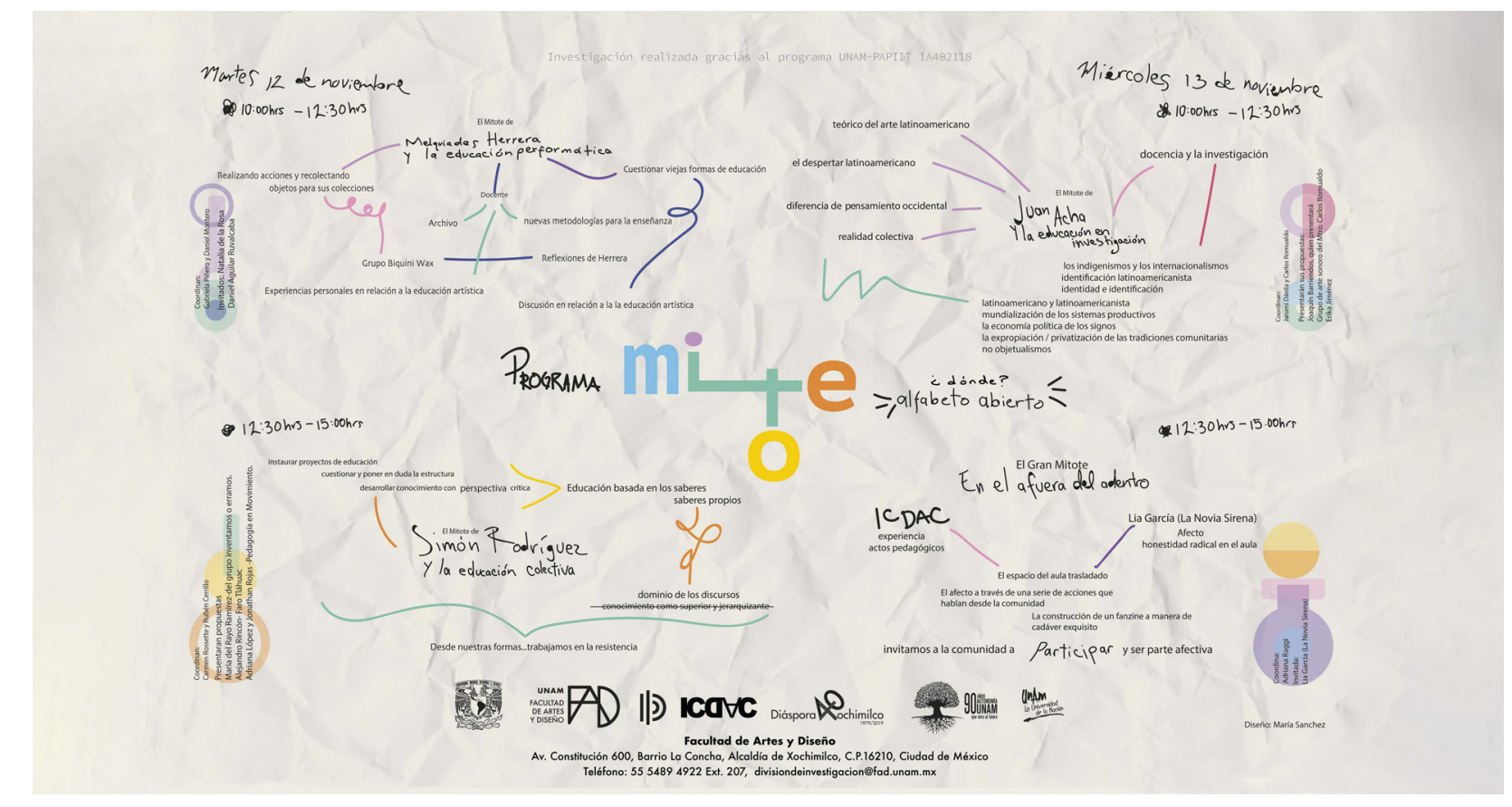

Fuente: Mitote ICDAC.

Resulta indispensable mencionar que proponemos estas formas de trabajo desde el aula pensando en derribar el muro, como la analogía de Pink Floyd en la que el profesor es un ladrillo en la pared que limita al estudiante (Pink Floyd, 1979), y resistir desde nuestras formas ante un sistema binario y jerárquico, para detonar, profundizar y expandir nuestros temas de investigación. A lo largo de la trayectoria del grupo hemos encontrado la colaboración como un territorio poco explorado en nuestra facultad, pero potentísimo, en primer lugar, en términos de formas de ver y narrar, ponderando la experiencia académica y el ejercicio profesional; en segundo lugar, en términos de la modificación de dinámicas no solo pedagógicas sino de mediación artística, diseñística, comunitaria, colectiva, de autogestión y de autoedición. 
Pensar la educación desde la colaboración.

Dossier

El Mitote como un trabajo colectivo

Para llegar a proponer lo anterior, tuvimos que detenernos a ver el trabajo realizado desde los inicios del grupo, en el año 2015, y muchos años antes como profesores que resistían la hegemonía académica desde otros discursos, otras trincheras y otros espacios. Podría decirse -imaginariamente- que siempre habíamos trabajado desde nuestras experiencias y observaciones, pero necesitábamos estar juntxs para poder enunciarlo comunitariamente, para que fuera un posicionamiento desde el nosotrxs y no desde ese Yo tan occidental. Esto nos llevó a nombrarnos a partir de nuestras experiencias y comportamientos individuales y colectivos con el fin de llegar a sabernos como un organismo que se ubica entre mitote y manada, donde las voces vertidas están inscritas en nociones no jerárquicas y que se promueva el cuidado a los procesos más que al resultado final. De ahí que nuestra propuesta más reciente y con la que hemos podido detonar y posicionarnos como docentxs e investigadorxs fueron los Mitotes de colaboración y exploración sobre la educación artística desde Simón Rodríguez, Juan Acha y Melquiades Herrera. Como ya dijimos, un mitote se define como una fiesta colectiva para el convivio, la charla cercana y la gratitud por la escucha desinteresada. Eso es lo que hicimos en la facultad, crear un mitote que también cuenta con la acepción de escándalo, encuentro ruidoso. Para esto, invitamos a la comunidad de la facultad a poner en discusión y a celebrar el trabajo y los procesos de cuatro personajes ligados a la educación en los Mitotes':

Melquiades Herrera y la educación performática: Melquiades Herrera (México, 19492003) fue un artista polifacético e irreverente. Impartió clases en la Escuela de Diseño del INBA y en la Escuela Nacional de Artes Plásticas (hoy FAD) de la UNAM. Artista pionero del performance en México y miembro del No-Grupo (1977-1983).

Simón Rodríguez y la educación colectiva: Simón Rodríguez (Nueva Granada, 1769-República Peruana, 1854) pedagogo y filósofo cuya vida extraordinaria y republicanismo radical siguen alentando el sueño del poder popular latinoamericano.

Juan Acha y la educación en investigación: Juan Acha (Perú, 1916- México, 1995) crítico, investigador, curador, productor de teorías, activista cultural y educador. Impartió clases en La Esmeralda del Instituo Nacional de Bellas Artes (INBA )y en la Escuela Nacional

- Las diversas actividades y presentaciones enmarcadas en el encuentro se desarrollaron en el Alfabeto Abierto -llamado así por el mural de Vicente Rojo que se encuentra en un espacio abierto a la circulación- de la Facultad de Artes y Diseño (plantel Xochimilco) de la UNAM.

ESCENA. Revista de las artes, 2021, Vol. 81, Núm. 1 (julio-diciembre), pp. 261-281 
de Artes Plásticas (hoy FAD) de la UNAM. Fue subdirector del Museo de Arte Moderno (MAM) entre 1972 y 1976. Es de resaltar su participación dentro del circuito cultural mexicano en el que fermentaron los grupos.

Gran Mitote. En el adentro del afuera: Lia García (México, 1989) performer, artista y pedagoga. Egresada de la FAD, activista feminista, defensora de los derechos humanos de las personas transgénero y cofundadora de la Red de Juventudes Trans México.

Los Mitotes retomaron observaciones pedagógicas y artísticas de cuatro figuras que oscilan entre su propia forma de docencia y la práctica artística, por lo que fue sumamente nutritivo empezar la colaboración con sus voces y quienes están cercanxs a su trabajo. Esto posibilitó lugares de la educación que no han sido tan explorados en las prácticas universitarias, sumó varias voces y maneras de ver y hacer y, sobre todo, propuso espacios y formas de la práctica artística que se desbordan en situaciones que inciden en contextos contemporáneos y significativos desde los territorios de la educación artística.

Imagen 2. Participación en el Mitote de Melquiades Herrera

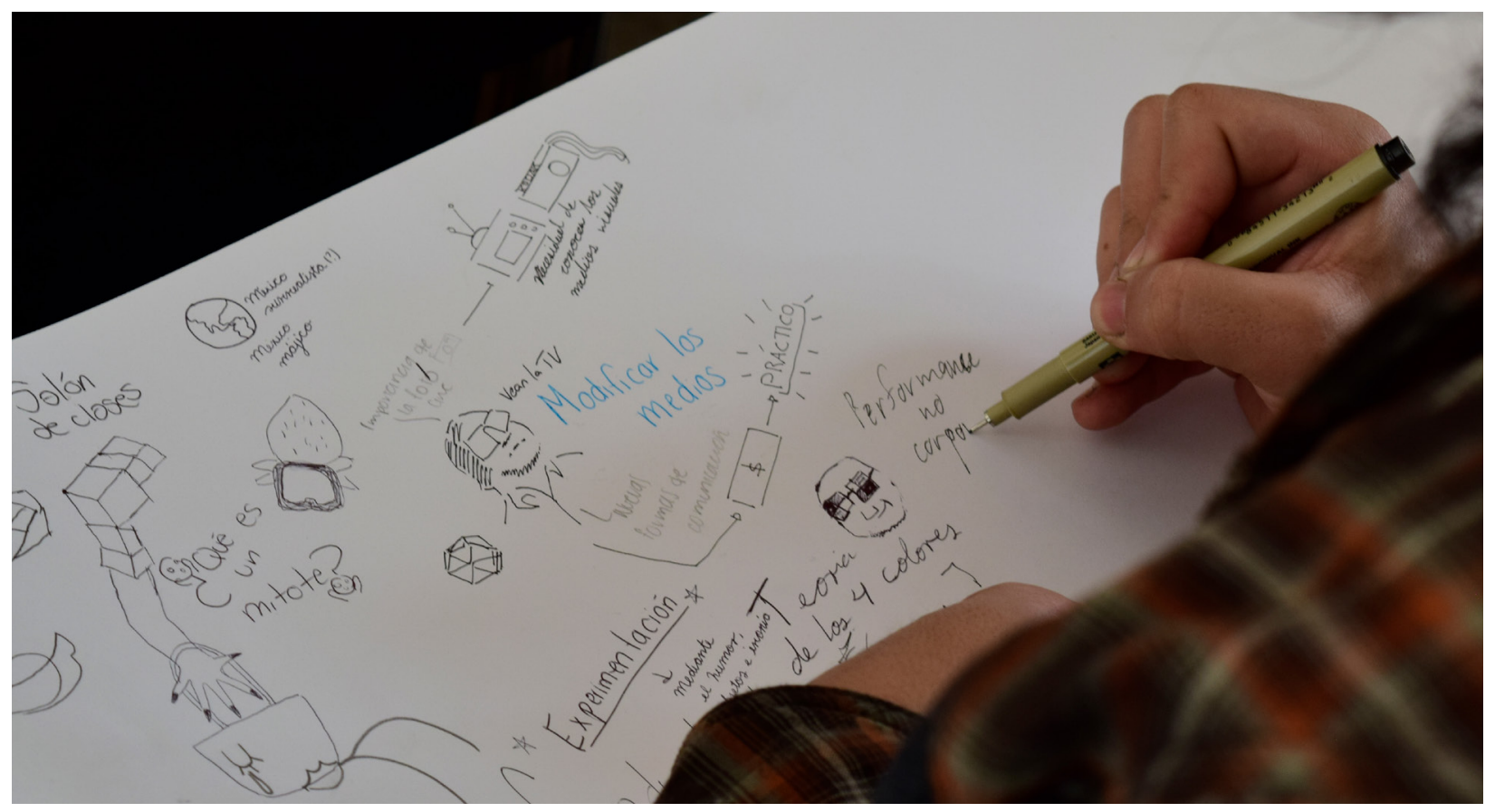

Fuente: Mitote ICDAC 
Pensar la educación desde la colaboración.

Dossier

El Mitote como un trabajo colectivo

Insistimos en poner en crisis aquellas ideas que dicen que hay que ver al artista en calidad de autor individual como la única manera de ejercer las prácticas artísticas, lo cual descansa en la idea de que la individualidad, desde la educación, es lo que la construye. En la tradición académica se reproduce la idea de un genio creativo como única vía aspiracional, a la que penosamente no todxs tienen acceso. Esto desencadena frustración, competitividad, desvalorización y violencia en nuestrxs estudiantes, olvidando e incluso invisibilizando las experiencias artísticas que han sido pensadas desde lo colectivo o lo comunitario y que son en realidad una mayoría; por ejemplo, la producción que los grupos de artistas hicieron entre la década de los años sesenta y los años ochenta en México, o en diferentes lugares de América Latina como procesos de resistencia a las dictaduras militares o políticas.

Es importante no olvidar todas esas iniciativas de mediación cultural que incluso hoy sostienen buena parte de las plataformas de ejecución de prácticas artísticas y que claramente son ignoradas por el relato hegemónico de la historia del arte. Esta es una narrativa que enseña a Ixs estudiantes a vivir en procesos de competencia, comparación y descalificación sistemática, y que anula por completo la posibilidad de trabajar en colectividad.

Enseñar desde otras narrativas, con la intención de resistir estos conceptos es un proceso difícil, porque en gran medida se trata de generar un desaprendizaje. Partir de lo que Ixs estudiantes entienden por arte y diseño o lo que entienden por comunidad, aprendizaje, educación, afecto o escuela es, en definitiva, un reto que demanda voluntad para resistir desde la responsabilidad educativa. Por esto, es que uno de los conceptos que cuestionamos es el de enseñanza-aprendizaje. No queremos ver la educación como ese lugar en el que existe unx profesorx que lo sabe todo y se lo va a enseñar (sin posibilidad crítica de réplica) a Ixs estudiantes quienes, desde su lugar asignado y manteniendo el orden, aprenderán obedientemente; buscamos fervientemente incentivar el pensamiento crítico no solo por la demanda profesional sino por el bien vivir comunitario desde la educación.

Desde que formamos el grupo, hemos pensado en la posibilidad de generar investigación desde los procesos de confrontación de ideas e intuimos que entre nosotrxs podíamos discutir en un terreno seguro, sin la amenaza presente de todos aquellos intereses cruzados que suelen arrastrarnos ya sea al terreno de la batalla o al de lo políticamente correcto, que muchas veces deforma el fundamento de las reflexiones que se generan a través de la experiencia colectiva. Por ello, retomamos a educadores como Simón Rodríguez, Juan Acha, Melquiades Herrera y Lia García, quienes han propiciado una educa-

ESCENA. Revista de las artes, 2021, Vol. 81, Núm. 1 (julio-diciembre), pp. 261-281 
ción que parte de lugares alejados de la dominación y acercados al diálogo entre iguales, construyendo un recurso experiencial que parta de una observación directa y que nos permita trazar mapas, genealogías y devenires.

Imagen 3. Participación en el Mitote de Simón Rodríguez

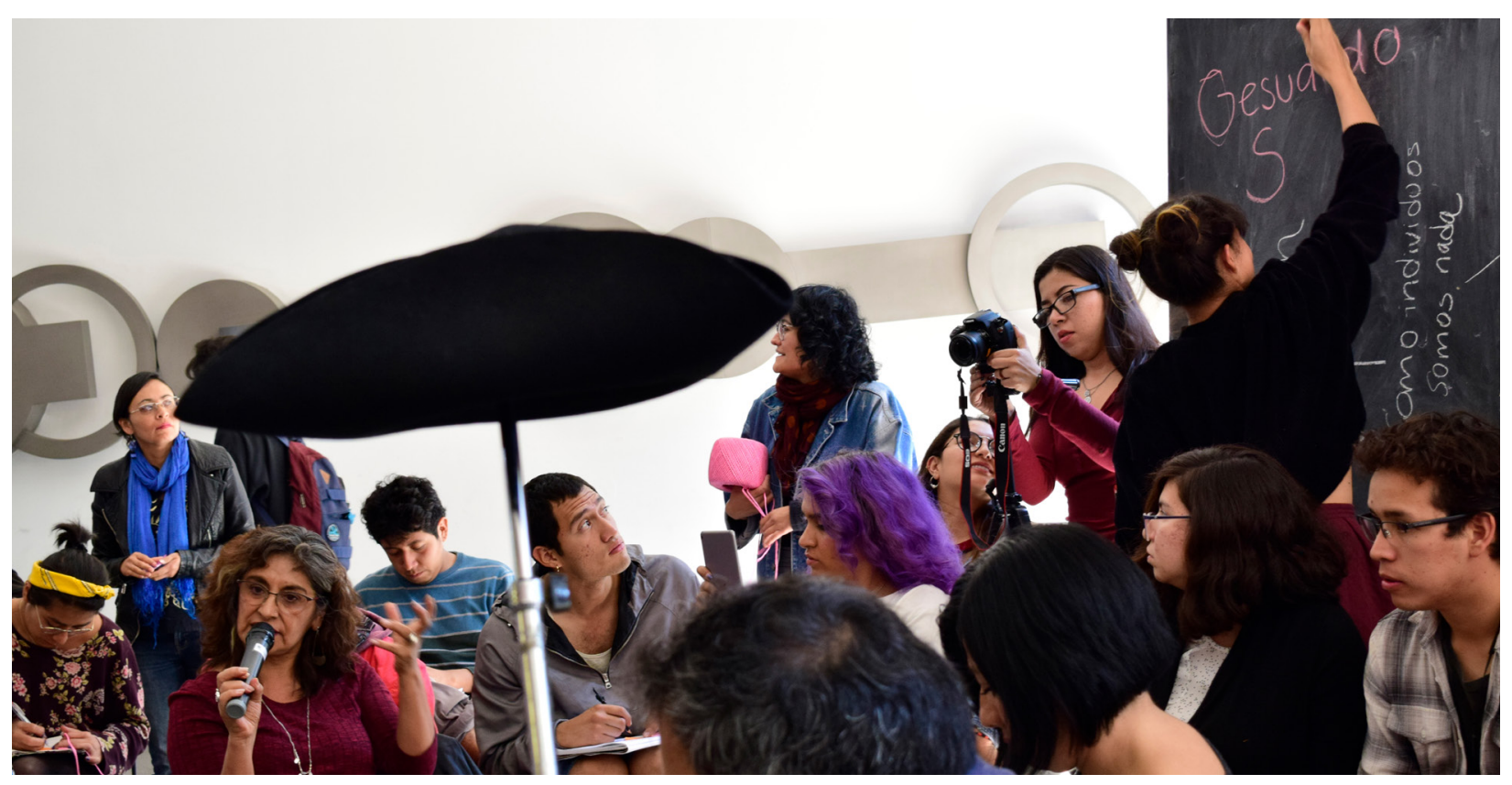

Fuente: Mitote ICDAC.

Pareciera que en este momento de pandemia mundial por la COVID-19 no sería urgente voltear a ver las estructuras educativas más rancias, sin embargo, a nosotrxs nos parece precisamente que es a donde tenemos que ver y cuestionar, porque la crisis sanitaria ha sacado a la luz grandes problemas del sistema educativo. Para desenmarañar lo anterior, queremos regresar a las enunciaciones puestas en el Mitote de Melquiades Herrera, en el que vimos una práctica docente de un artista en la Escuela Nacional de Artes Plásticas (ENAP) que incluía una forma de cuestionamiento a las viejas formas de educación que ya no se ajustaban a las prácticas artísticas contemporáneas. Desde ahí, proponía nuevas metodologías para la enseñanza. Notamos que poner sus reflexiones sobre la mesa y a la mano de todxs detonó diálogos colectivos que insinuaban, como bien pensó Herrera, una ruta para realizar el cambio y cuestionar las capacidades que una Facultad debe tener para llevar a cabo tal propósito. 
Pensar la educación desde la colaboración.

Dossier

El Mitote como un trabajo colectivo

Para dar continuidad a lo anterior, sumamos el Mitote de Simón Rodríguez, cuya idea de proyecto educativo (que hoy en día entenderíamos como educación popular) compartimos ampliamente. La propuesta de este educador no solo integraba a Ixs niñxs de todos los orígenes y etnias, sino que también permitía desarrollar conocimiento con una postura crítica, que les hiciera posible cuestionar y poner en duda la estructura que los tenía en las condiciones paupérrimas que experimentaban en la colonia en el siglo XIX. Además, en esa línea, cuestionó la colonia y los signos de destrucción de la cultura que había en ese momento en los territorios de América, de ahí su frase más emblemática: O inventamos o erramos, como una forma de decolonizar el pensamiento nuestroamericano. Esto nos hizo ver, con más claridad, la urgencia de proponer y ejercer otras formas de pedagogías que se basen en los saberes y condiciones ligados a la situación de los lugares que las contenían, es decir, desde el conocimiento y el aprendizaje situado, para lograr con ello una forma contextual de pensamiento y autonomía ligada a los saberes propios.

Nos interesa hacer hincapié en la resistencia que Rodríguez hacía frente al dominio de los discursos que ostentan cierto tipo de conocimiento como superior y jerarquizante, lo cual genera la idea de que Ixs unxs (las mayorías) tienen mayor importancia respecto de Ixs otrxs (las minorías). Si pensamos que las estructuras, las instituciones y las formas de vida no se toman como modelo a las propias prácticas y saberes de la América, estamos condenados a repetir la estructura de dominio.

Simón Rodríguez se empeñó en crear comunidades que pudieran traer una libertad sustentable en América Latina. Como nos cuenta Rafael Mondragón (2020):

Rodríguez intentó construir: un sistema de escuelas experimentales en Chuquisaca, en el nuevo país de Bolivia... La historia detallada de este proyecto fallido está contada en las cartas exasperadas del mariscal Sucre, quien se quejaba constantemente de que Rodríguez quería pagarle bien a los maestros y que estaba mandando recoger a los jóvenes desposeídos de la ciudad (que para Sucre no eran sino "muchachos, mujeres perdidas y holgazanes") para que vivieran adentro de la escuela.

Más que un internado, se trataba de una comunidad. Como suma prueba de inmoralidad, la gente señalaba que la escuela experimental de Rodríguez estaba abierta para niños y niñas y permitía que ellos y ellas hicieran vida en común. La casa que era su sede tenía habitaciones acondicionadas como talleres, en donde

ESCENA. Revista de las artes, 2021, Vol. 81, Núm. 1 (julio-diciembre), pp. 261-281 
se aprendían oficios al mismo tiempo que se enseñaba a leer, escribir y hacer cuentas. Los padres y madres eran parte de la pequeña comunidad: si podían trabajar, se les daba ocupación; si eran inválidos, se les socorría por cuenta de sus hijos. La comunidad de Chuquisaca buscaba construir, en el mediano plazo, su autonomía económica respecto del gobierno. Imaginaba que la convivencia allí ensayada podía construir un nuevo país: la idea de Rodríguez era articular el proyecto educativo con un proyecto de reforma agraria, para que a cada niño se le asignaran tierras y se le ayudara a establecerse para colonizar el país con sus propios habitantes... Y también -escribió él- para que las niñas no se prostituyesen por necesidad, ni hiciesen del matrimonio una especulación para asegurar su subsistencia (Mondragón, 2020, parr. 14-15, destacado de las autoras).

Con estas voces nos entusiasma pensar que una educación crítica, decolonial y antihegemónica es posible. Por ello, en el Mitote de Juan Acha propusimos retomar su pensamiento más revolucionario, resaltando la afinidad que tenemos con su espíritu crítico y agitador, el cual lo llevó a tomar conciencia de la diferencia de pensamiento con Occidente. Se reconoce un pensamiento y una actitud acorde con su realidad colectiva, una idea de transformar la realidad latinoamericana, indagando sobre los conceptos de identidad e identificación, lo que dio pie a reflexiones sobre la mundialización de los sistemas productivos, la economía política de los signos, la expropiación-privatización de las tradiciones comunitarias $y$, con ello, la idea de que el conocimiento se impone ante los saberes.
Imagen 4. Participación en el Mitote de Juan Acha

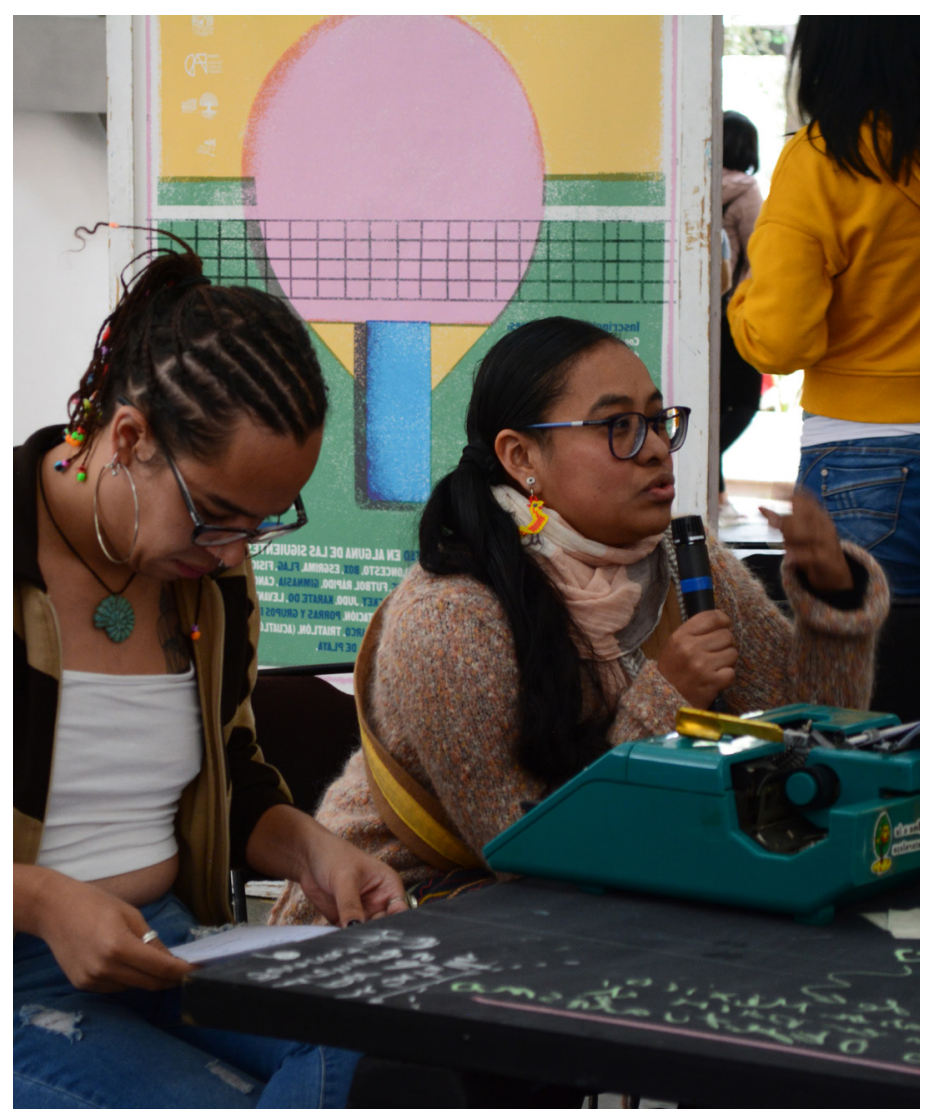

Fuente: Mitote ICDAC. 
Pensar la educación desde la colaboración.

Dossier

El Mitote como un trabajo colectivo

Juan Acha fue un personaje que buscó despertar una nueva forma de hacer arte; en múltiples sentidos lo logró y, en muchos de esos, nosotrxs nos sentimos atraídxs a conceptos que hemos trabajado y que no recordamos hasta qué punto hemos heredado de sus textos. Pensamos en cómo:

Decidido a sustituir las obras con acciones y a desplazar la prominencia de los objetos vendibles para dar lugar a los procesos artísticos, en diciembre de 1969 participa en una nueva experiencia a medio camino entre la curaduría, el happening y la desobjetualización. Invitado por su amigo, el poeta Jorge Eduardo Eielson, Acha fue convocado para activar poéticamente una de las nueve Esculturas subterráneas que Eielson había "enterrado" previamente en diferentes ciudades, esculturas que habrían de ser leídas sincrónicamente en una acción denominada Esculturas para leer (Barriendos, 2017, p. 28).

Juan Acha trabajó desde lo revolucionario en el arte, desde entenderlo como procesos artísticos y no como la producción de objetos. Es, tal vez (porque a veces no sabemos de dónde aprehendemos las ideas), desde ahí que nos hemos acercado a la idea de prácticas artísticas y que hemos construido dentro de los procesos del grupo en nuestras aulas, y cuando nos desplazamos de ellas, una idea de enseñanza que cuestiona el taller como espacio único de producción y el salón de clases (supuestamente de teoría) como espacio del análisis y comprensión de la teoría del arte.

Nosotrxs tratamos de generar a través del concepto de investigación artística una práctica que no divida binariamente al arte: teoría-práctica. También pretendemos cuestionar el binarismo que nos acompaña en la vida, que nos vuelve una sociedad basada en la violencia y que, por lo tanto, lo llevamos al salón de clases. Es desde un pensamiento heteronormativo y binario que se construye una sociedad violenta, por eso, nosotrxs intentamos cuestionar esta construcción social que nos mete en una camisa de fuerza. Pensamos como Brigitte Vasallo que:

Hay que ir desmontando paso a paso, no desde el tejado, sino buscando los cimientos, comprendiendo qué sustenta ese lugar, qué partes son accesorias, cuáles son mera decoración y cuáles son las partes esenciales de esa casa. Y buscar, también, las vías de escape y las maneras para hacer caer la construcción sin dejarnos el pellejo dentro. Esos cimientos son, por un lado, el sistema sexo-género binario que sustenta toda la estructura de co-dependencia reproductora entre 
los hombres y las mujeres a través de la romantización de los deseos y los afectos; y, por otro lado, las dinámicas de la jerarquía, la confrontación y la exclusión, que se sustentan en el capitalismo afectivo. Esos son los cimientos a los que tenemos que apuntar (Vasallo, 2019, p. 28).

A partir de ese cuestionamiento es que hemos llegado a trabajar con la idea de afecto, pero aquel que desmonta al capitalismo afectivo y a las relaciones de dominación desde el entendimiento de la palabra misma.

Imagen 5. Participación en el Gran Mitote

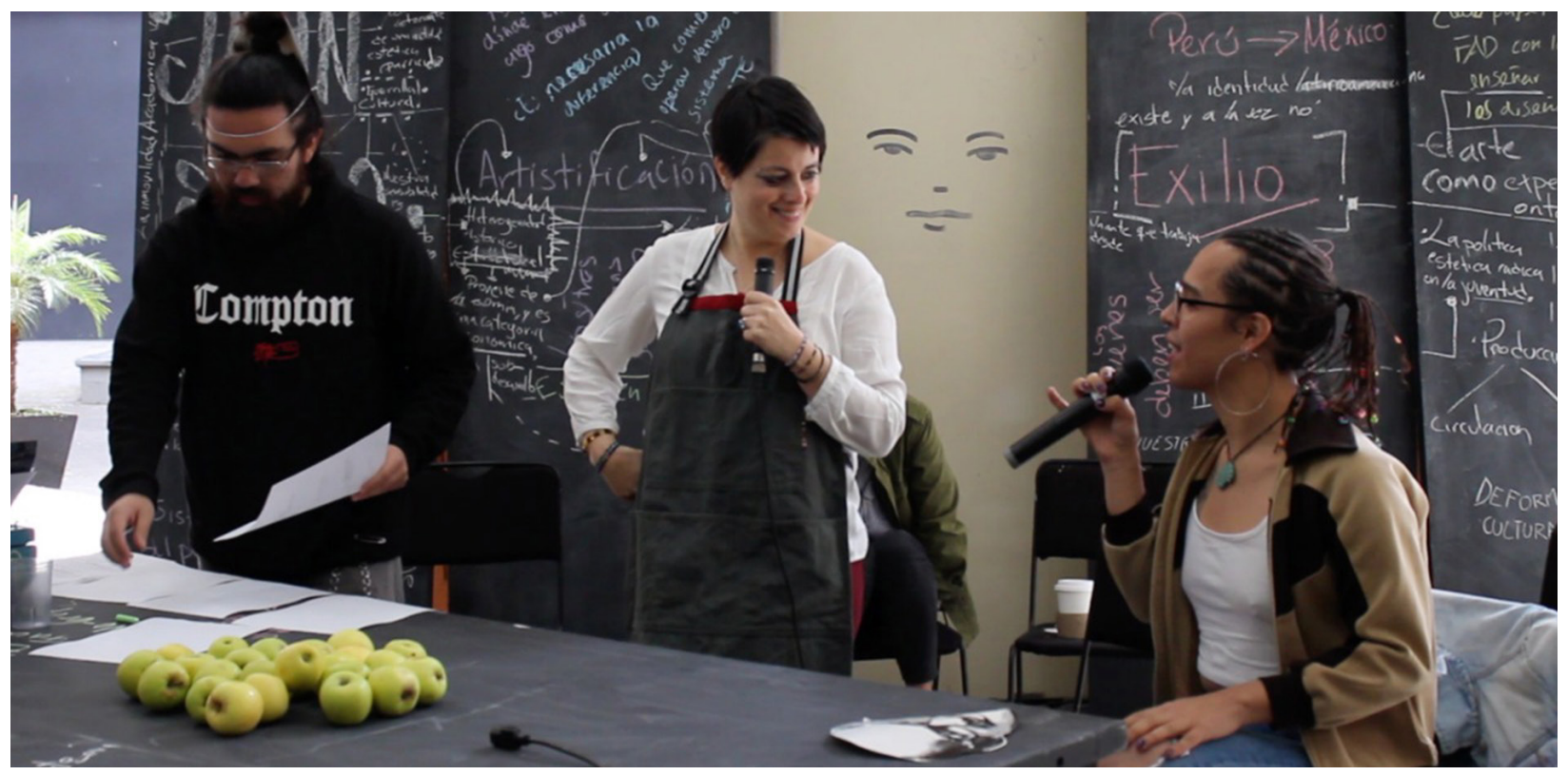

Fuente: Mitote ICDAC.

Una de nuestras búsquedas más radicales se deriva de nuestra experiencia y conocimiento del afecto y su relación con la honestidad radical en el aula. Creemos que estos dos conceptos y formas de enseñanza posibilitan espacios académicos seguros, significativos y potenciales para una formación profesional que considere al buen vivir como su centro. De nuestro trabajo con el concepto de afecto y su relación con los actos pedagógicos encontramos en lo individual y lo comunitario, entre docentes, adjuntxs y estudiantes, una compartición de saberes a partir de una serie de acciones que suman afectivamente. Tal fue el caso del Gran Mitote, donde participó Lia García, quien se define como: 
Pensar la educación desde la colaboración.

Dossier

El Mitote como un trabajo colectivo

Escritora, pedagoga y artista del performance. Junto con su hermana de greñas Jessica Marjane co-fundó la Red de Juventudes Trans en 2016. La apuesta política y pedagógica de Lia la sirena ha sido, por más de 10 años, un trabajo con los afectos y la ternura radical, principalmente en espacios de complejidad que socialmente se entienden como encierros (cárceles, escuelas, mercados, comunidades, territorios post-guerra externos e internos y hospitales, entre otros). Su activismo parte de la piel y transita al arte entrecruzado por la poesía expandida. Ella detona una pedagogía intensa del amor que recupera el sentido afectivo de nuestros cuerpos y subjetividades, alejándose de procesos racionales y teóricos para emanar un proceso colectivo de justicia restaurativa que permita que los cuerpos trans ${ }^{\star}$ sanen y materialicen todos los mundos y cuentos posibles que habitan sus sueños. ¿Quién no se ha incomodado con ella? ¿Quién no se ha mirado en ella desde la luz y desde la propia sombra? ¿Cómo dejar de extrañar el mar? ¿Cómo se puede ser sirena sin las lágrimas propias? ¿Cómo dejar de ser una y ser "las otras"? Ella es Lia (García, Comunicación personal, 26 de noviembre de 2020).

En el Gran Mitote, el cual se centró en el trabajo con el afecto7 desde la pedagogía, se realizó una práctica artística que consistió en tejer a través de la corporalidad un gran nudo que partía de las emociones y de una experiencia del tejido de la palabra a través de la compartición de la comida, en este caso una manzana. Lo que se generó fue un espacio de curación de las emociones recibidas desde una educación violenta. Compartimos lo que nos hicieron y también lo que hicimos a Ixs demás.

En suma, lo anterior nos hizo ver que el Mitote fue un punto crítico para gestionar los afectos desde el espacio universitario; en él desarrollamos (nosotrxs y lxs otrxs) nuestras ideas y sentires sobre sobre el cuerpo y su relación con la experiencia educativa, pues es desde aquí que comienza a gestarse la normalización y los mecanismos de control del poder. Este control se expresa en la educación cuando se pretende eliminar la idea del afecto en el aula, para imponer la concepción de que el cuerpo y la mente son dos elementos diferentes (por tanto, administrables desde el privilegio de quienes se supone que poseen el conocimiento) en donde la mente es superior y el cuerpo es un mal necesario que no aporta ni significa nada en esa viciada esfera del conocimiento validado. En el Mitote ICDAC

7 Es importante entender que el acoso no es una forma de afecto sino una forma de violencia de las que cuestionamos.

ESCENA. Revista de las artes, 2021, Vol. 81, Núm. 1 (julio-diciembre), pp. 261-281 
pensamos que no existe separación entre cuerpo y mente (algo que el feminismo nos ha enseñado). Creemos que bajo esta visión existe la posibilidad de generar conocimiento crítico, cercano, compartido y entrañable.

\section{Nuestras reflexiones}

Para Mitote ICDAC es necesario enunciar que creemos en la educación desde la colaboración y desde ese planteamiento trabajamos y proponemos. Por tanto, en estos haceres están selladas las ideas de educación y comunidad como pilares de nuestras propuestas. Siempre hemos procurado incluir varias voces, espacios y formas de ver y actuar en la educación y la comunidad, al tener una discusión abierta y nutritiva de aquellas reflexiones que nos implican, que nos son imprescindibles, que nos permiten, sobre todo, construir comunidad alrededor de preocupaciones y sueños compartidos. Partimos desde la educación como profesión, pero la ejercemos desde y con la comunidad porque entendemos que si lo hacemos juntxs trasciende territorios de saberes y de sensibilidades que sí son significativas y reales a nuestros cotidianos. Ponderamos la idea de que los procesos educativos, desde nuestro punto de vista, deben ser integrales y colaborativos, resistiendo a su actual estado incompleto, pues pareciera que el afecto, lo colaborativo y la otredad no están en el salón de clases, que estamos condicionadxs a repetir y memorizar, que nuestras miradas no se cruzan y que solamente estamos ahí para generar un conocimiento técnico, sistemático y totalmente ajeno a los procesos y experiencias, tanto de Ixs alumnxs como de nosotrxs, como parte activa de un espacio que pretende generar un conocimiento compartido.

Con estos Mitotes pusimos sobre la mesa un cambio que incluye aceptación, estudio, entendimiento, desarrollo, manejo crítico y consciente de las implicaciones que tiene la colaboración, las cuales pueden ser tejidas como un factor crucial en el desarrollo de todos los procesos que vivimos y compartimos en el aula. Como un grupo de profesores cuya politización está colocada en el bien vivir comunitario, como forma de estar y aprender desde la universidad pública, resistimos a un sistema educativo que ha generado y sostenido la idea de que el control sobre Ixs estudiantes es la forma correcta para construir saberes, ya que solo Ixs profesorxs son los dadores de saber. Son puntos de conflicto constante para nosotrxs, pues pensamos y vivimos desde la idea de que lo colaborativo es una forma perfectamente válida para buscar un cambio a través del replanteamiento de las relaciones dentro y fuera del aula. 
Pensar la educación desde la colaboración.

Dossier

El Mitote como un trabajo colectivo

De ese modo, con la idea de educación colaborativa pretendemos articular espacios seguros y autogestivos desde donde se pueda cuestionar al sistema que mantiene la colonización y la jerarquización del arte, el diseño y la educación como algo a lo que debemos sumarnos y acostumbrarnos de manera dócil. La educación colaborativa está impregnada de aprender en el mundo y no aprender para el mundo, resiste desde la experiencia de la vida que nos implica, porque vivimos cada día en ella y no es cuantificable ni validable.

Este es un trabajo arduo, porque significa cuestionar nuestra propia educación, la que recibimos en esa misma facultad y en la que hemos estado transitando desde que aprendimos a relacionarnos, para después cuestionar la que nosotrxs impartimos y finalmente la que Ixs estudiantes viven. También significa entender cómo es que nosotrxs hemos contribuido a un sistema que no permite otras formas de pensar, a la vez que pretendemos reivindicar la educación del vivir que se reconozca socialmente y no la que estandariza a lxs sujetxs.

Poner el cuerpo dentro de lo colaborativo no significa solamente convivir; significa ocupar el espacio y mostrar, de muchas formas, cuando nos interesamos Ixs unxs por Ixs otrxs, cuando estamos conscientes de que son los saberes compartidos a través del afecto y lo valioso de tejerlo con otrxs los que nos ayudarán a gestar un mundo que no parta de dos géneros que viven de la individualidad, la competencia y la violencia, sino que admita que somos muchos géneros, muchos saberes, muchas formas de ser y estar en este mundo. En ese sentido, la pandemia que vivimos hoy es complicada; no sabemos qué sucederá y pareciera ser que no tenemos las herramientas suficientes para enfrentarla, pero tenemos que buscar en todas las propuestas que han existido más allá de un sistema capitalista al que no le importa el bien vivir de la gente. Si como dice bell hooks "Love is an action, a participatory emotion. [el amor es una acción, una emoción participativa]"8 (hooks, 2001, p. 165), los procesos educativos en los que el Mitote ICDAC teje son también participativos y precisamente afectivos. Ante la emergencia re-configuramos nuestra forma de compartir con Ixs otrxs. Al observar a lo que hemos estado expuestxs todxs: exceso de pantallas, cansancio colectivo, temor al presente y al porvenir, el insistente e insensible cumplimiento de normas que no corresponden a lo vivido, donde pareciera que las prioridades no son por el bien vivir sino el seguir produciendo, partimos de la elección de no usar únicamente los medios virtuales para la educación.

${ }^{8}$ Las traducciones son nuestras con propósitos de este texto

ESCENA. Revista de las artes, 2021, Vol. 81, Núm. 1 (julio-diciembre), pp. 261-281 
Durante estos meses de reclusión, que la prioridad sea no parar de producir ante el problema trae consigo el despojo de las sensibilidades y de la posibilidad de pensamiento crítico construido en la educación pública. Notamos y somos partidarixs de desvincular la competencia como norma para validar una jerarquía académica ante cualquier adversidad, por muy violenta que sea esta, y apostamos por la esperanza de aprendizajes colaborativos y posibles que rimen con las situaciones que vivimos y cómo nos adaptamos a ellas, para así relacionarnos con lxs otrxs.

Por lo anterior, enunciamos que cuando somos rebeldes desde las aulas y vemos lo que sí ocurre y no lo que quieren que veamos, cuando volvemos a sentir y no solo a reproducir, cuando vemos a los lados y nos encontramos acompañadxs, hacemos y construimos electivamente, nos sinceramos con nosotrxs y con Ixs otrxs para rechazar las estructuras individuales y poner sobre la mesa preguntas que nos atraviesan, que entendemos y que no necesitamos ficcionar. De ahí que nos identificamos con la labor educativa de bell hooks (2003) y la esperanza que ella encuentra en el trabajo en el salón de clases como una comunidad:

My hope emerges from those places of struggle where I witness individuals positively transforming their lives and the world around them. Educating is always a vocation rooted in hopefulness. As teachers we believe that learning is possible, that nothing can keep an open mind from seeking after knowledge and finding a way to know. [Mi esperanza surge de los lugares de lucha en donde soy testigo de individuos que transforman positivamente su vida y el mundo que les rodea. La educación es siempre una vocación arraigada en la esperanza. Como profesores creemos que el apren-

Imagen 6. Los Mitotes

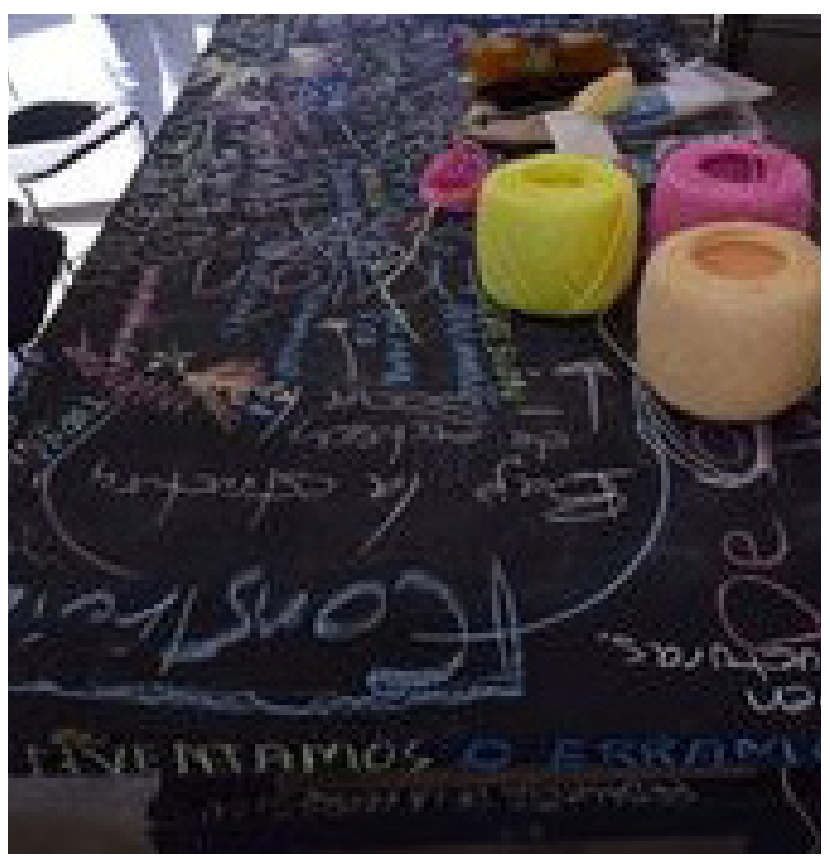

Fuente: Mitote ICDAC. 
Pensar la educación desde la colaboración.

Dossier

El Mitote como un trabajo colectivo

dizaje es posible, que nada puede evitar que una mente abierta busque conocimiento y encuentre una manera de saber (hooks, 2003, p. xiv).

Con cada mitote confiamos en el tejido colaborativo que se genera en los saberes vertidos que se desbordan; sobre todo, confiamos en la forma en la que se resignifica a partir de las prácticas de quien las vuelve parte de su accionar. Propiciamos, también, nuevos territorios en los que germine y se vuelva a tejer, para conectarnos con quienes se involucren y así construir otro mitote. De igual manera, tenemos certeza de que esta forma de trabajo puede estar o surgir en cualquier espacio que así lo quiera, pues no es una imposición académica y no necesita de una figura jerárquica que lo apruebe, sino que se teja una propia validación colectiva que sume a las nociones de aprendizaje y educación colaborativa, autogestiva y autonarrativa, la cual -a través de acompañarnos en los procesos de vida- pueda posicionarse en el mundo y no sobre él.

\section{A donde vamos}

En este texto hemos ahondado en lo sucedido en los Mitotes de colaboración educativa, por lo que hemos abordado varios aspectos y reflexiones generadas en estos eventos académicos, y su impacto en el espacio educativo y la comunidad. Podemos declarar que los Mitotes lograron dejar un precedente sobre lo que Mitote ICDAC considera una visión de la educación no violenta a través de lo cual pudimos pensar y ejercer otras formas de construir el aula por medio de varias herramientas (como se observar en las fotografías que acompañan a este texto, utilizamos una máquina de escribir colectiva, unos tableros intervenibles y tejimos saberes en un cadáver exquisito).

Desde lo ocurrido, consideramos que estas herramientas aportaron a la activación del espacio y a la inclusión de los participantes en un proceso comunitario, lo cual fue determinado por el espacio que elegimos. Lo anterior nos llevó a notar que las herramientas utilizadas sirven para llevar a cabo un acompañamiento educativo, que se formó con elementos como la relatoría, la autoedición y el trabajo de archivo tanto en su construcción como en su utilización. Desde el evento hasta este artículo hemos hecho evidente que si queremos revertir el vigilar y castigar de Foucault (2002) debemos considerar que el saber y la educación deber ser siempre situados.

ESCENA. Revista de las artes, 2021, Vol. 81, Núm. 1 (julio-diciembre), pp. 261-281 


\section{Referencias}

Acaso, M. (2018). Pedagogías invisibles: El espacio del aula como discurso. Madrid: Catarata.

Barriendos, J. (2017). Juan Acha. Despertar revolucionario-revolutionary awakening. Ciudad de México: Museo Universitario Arte Contemporáneo.

Camnitzer, L. (2012). La Enseñanza del arte como fraude. Esferapública. [Entrada de blog]. Recuperado de http://esferapublica.org/nfblog/la-ensenanza-del-arte-como-fraude.

Klorenzini. (29 de setiembre de 2011). [2ndo. coloquio] Coloquio construcción utópica y lucha social 15.mov [Archivo de video]. Recuperado de https://youtu.be/OPIMiAU7Q4Y

Corona, A. (2018). Mecanismos de otrificación entre la oposición política en Twitter durante las elecciones estatales de 2017 en México. AdComunica, 16, 45-70. DOl: 10.6035/2174-0992.2018.16.4

Foucault, M. (2002). Vigilar y castigar. Nacimiento de la prisión. Buenos Aires: Siglo XXI.

Freire, P. (2005). Pedagogía del oprimido. México: Siglo XXI.

Helguera, P. (2011) Education for Socially Engaged Art. Nueva York: Jorge Pinto Books.

hooks, b. (2001). All About Love. New Visions. Nueva York: HarperCollins.

hooks, b. (2003). Teaching community. A Pedagogy of Hope. Nueva York: Routledge.

Klüser, B. (2006). Joseph Beuys, Ensayos y entrevistas. Madrid: Síntesis.

Mondragón, R. (28 de octubre de 2020). Simón Rodríguez, demonio de los mesones. Jacobin. América Latina. Recuperado de https://jacobinlat.com/2020/10/28/simonrodriguez-demonio-de-los-mesones/

Pink Floyd. (1979). Another Brick in the Wall [cancion]. En The Wall. Capitol Records.

Vasallo, B. (2019). Pensamiento monógamo. Terror poliamoroso. Madrid: La oveja roja. 